\title{
Stress and Coping Strategies among Management and Science University Students: A Qualitative Study
}

\author{
Redhwan AANa, Sami ARa, Karim AJa, Chan R' and Zaleha Mlc \\ ${ }^{a}$ Medical Science Department, Management and Science University, Malaysia \\ ${ }^{b}$ School of Medicine, Monash University, Malaysia \\ 'Community Health Department, National University of Malaysia, Malaysia
}

\begin{abstract}
Introduction: This study aimed to explore the associated factors related to causes of stress and coping strategies among university students. Materials and Methods: As a focus group discussion, it was universal sampling, conducted among 39 of Medical Science and Biomedicine students on their second semester from Management and Science University (MSU), Shah Alam, Malaysia. Three issues were discussed: firstly, how they define the stress; secondly, what the most important causes of stress in their life are; and thirdly, how they cope with stress. Verbal consent was obtained from all participants. Due to the small sample size, the data was analyzed manually. Results: Total of participants were 39 students, their age ranged from 21 to 26 years. Seventeen (43.6\%) of the students were 21 years old and the majority were female 31 (79.5\%). The most important causes of stress reported by the students were financial, lack of sleep, and family problems. In terms of coping with stress, the students were able to describe a variety of strategies to cope with their stressful situations. These included counseling services, doing meditation, sharing of problems, getting adequate sleep, and going out with friends. Conclusion: Most of the students defined stress as "a mental condition". Lack of sleep, financial, and family problems were the most causes of stress among students. The students were able to identify some strategies to cope with stress.
\end{abstract}

KEYWORDS: Malaysia, Qualitative study, Stress and coping, University students

\section{INTRODUCTION}

Stress is seen as modern society's illness by professionals from different sectors. It has effects on people's behaviors, communications and efficiency. Stress was described as a relationship between individuals and their environment that is appraised as dangerous and evaluated as beyond their ability to deal with stress. ${ }^{1}$ Selye defined stress as a physiological non-specific reaction to external or internal demands. ${ }^{2}$ Therefore, it is not the stressor that causes stress but the individual's perception and emotional reaction to it. University students are exposing to very stressful situations. ${ }^{3}$ The problems encountered by students may differ from those faced by their nonstudent peers. The pressure to get good grades and to get a degree is very high. ${ }^{4}$ Getting high grades is not the only source of stress for students, also there are other important sources of stress, which included homework, assignments and uncomfortable classrooms. ${ }^{5}$ In addition

Corresponding author;

Redhwan Ahmed Al-Naggar

Medical Science Department,

Faculty of Health and Life Sciences,

Management and Science University,

Malaysia

E-mail: radhwan888@yahoo.com to academic requirements, relationships with faculty members and time pressure may also be sources of stress. ${ }^{6}$ Relationships with family and friends, eating and sleeping habits and loneliness may affect some students on an average. ${ }^{3,7}$

Coping strategies are defined as the person's constantly changing cognitive and behavioral efforts to manage specific external or internal demands that are appraised as taxing or exceeding the persons resources. ${ }^{8}$ Previous research showed that students with an active coping style have lower levels of psychological distress. ${ }^{9}$ In view of the potential long term benefits of managing stress in a more effective way, it may be important for students to develop such skills early in their medical career. Stress is not only happens at workplace but students are subjected to different kinds of stressors, such as the presence of the academics with an obligation to succeed, an uncertain future and difficulties of integrating into the system. The students faced social, emotional, physical and family problems which might affect their learning ability and academic performance. As a result, it is important that individuals develop different 
strategies in order to manage stressful situations. ${ }^{10,11}$ In terms of stress management, Lazarus and Folkman defined eight separate coping strategies that they believed individuals employed in stressful situations. ${ }^{12}$ These are confrontation, seeking social support, planned problem-solving, self-control, accepting responsibility, distancing, positive reappraisal, and escape/avoidance.

In Malaysia, handful studies conducted related to stress and coping styles were focused on stress among nurses, international school students, school athletes, university students, medical students and among prescience students. ${ }^{13-18}$ This is the first kind of qualitative study conducted to look up at stress and coping strategies among university students. Therefore, this study aimed to explore the associated factors related to causes of stress and coping strategies among university students.

\section{METHODOLOGY}

This qualitative study as a focus group discussion was conducted in May 2009 among 39 Biomedicine and Medical Science students from Management and Science University (MSU), Shah Alam, Malaysia. Universal sampling used to conduct this study. They were on second semester of their study. Verbal consent was obtained from all participants. The students were divided into five focus groups; each group consisting of 8 students except one group of seven students. The main author was the facilitator for group discussion. The facilitator asked probe questions and directed the group discussion in which all students participated and were given equal time for discussion. The facilitator wrote down the conversation during the discussion. Three issues were discussed: first, how they could define stress, second, what the most important causes of stress in their life were, and third, how they cope with stress. The data obtained were classified into various categories. Due to the small sample size, the data was analyzed manually.

\section{RESULTS}

\section{Socio-Demographic Characteristics}

Total of participants were 39 students, their age ranged from 21 to 26 years. 17 (43.6\%) of the students were 21 years old and the majority were female: 31 (79.5\%). More than half of students were Indian 23 (59.1\%), followed by Malay 8 (20.5\%), and then Chinese 4 (10.2\%). Four students were from other races (Punjabi, Iban, Eurasia and Kadazan). Most of the students were single: 38 (97.4\%), while one student was married (Table 1).

Table I. Demographic characteristic of students $(n=$ 39)

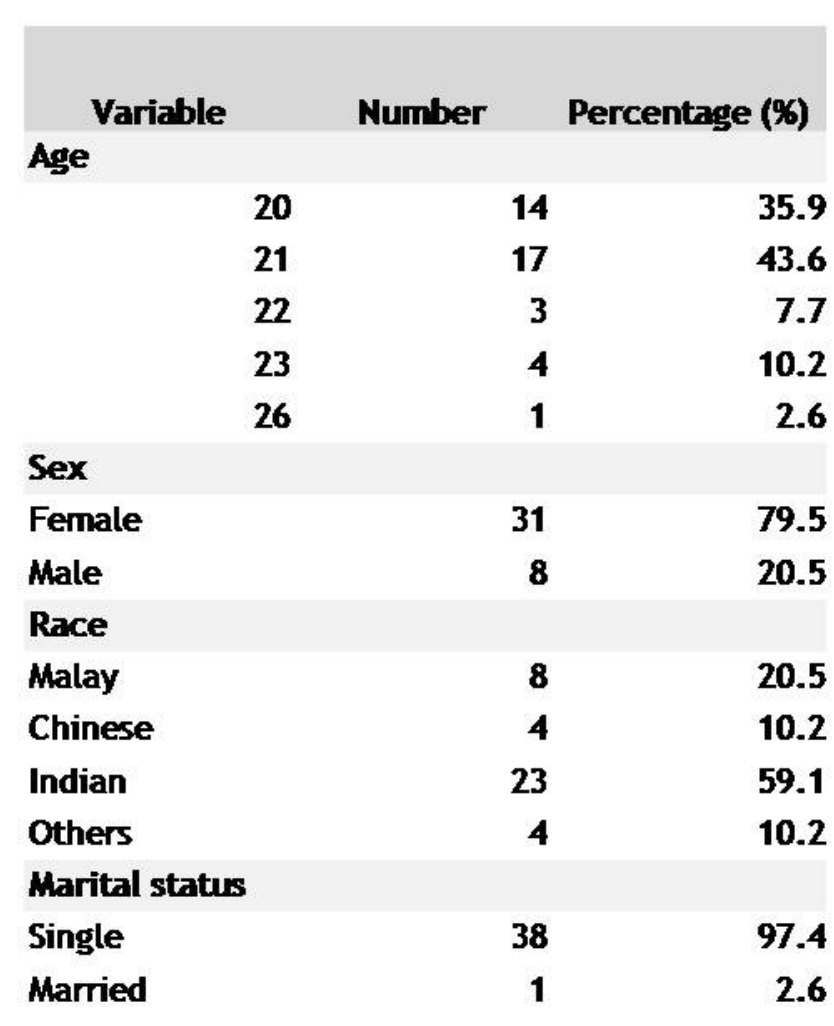

\section{Stress Definition}

Five definitions of stress could be summarized from this study:

Definition 1: Stress is a state of mind being under pressure which is caused by conflicting outer and inner self factors, experienced by all categories of age and gender.

Definition 2: Stress is a situation when people tend to focus on the negative feelings and emotions it produces.

Definition 3: Stress is a condition of mental pressure for particular individual facing problems from environmental and social well-being which leads to so many diseases.

Definition 4: Stress is a state of worry experienced by a person in particular circumstances such as environment/ surrounding and physical, mental, and social conditions, etc.

Definition 5: Stress is unstable emotions that lead to piling which disables us to think wisely.

\section{Causes of Stress}

Students experience a variety of stressful events during their life but the most causes of stress reported by groups are financial, lack of sleep, and family problems. All the students reported that the financial factor was the main cause of stress.

"Finance pressure may arise to over budget, house- 
hold expenses, and house bills."

Indian, 21, female, single

The majority of the students reported that lack of sleep was one of the important causes of stress followed by family problems.

"Conflict between husband and wife may affect the mental health of both marital partners and even their children." Malay, 23, Male, single

Some of the students reported that the study was one of the causes of stress.

"We feel pressured or stressed from exam tension, last minute preparation for exams and assignment." Indian, 23, Female, single

Other causes of stress mentioned are acceptance by the partner

"Teen might feel stress to make herself feel accepted by his or her peers."

Indian, 20, female, single

Other less important causes of stress reported were loneliness, conflict with own belief, poor time management, unhealthy diet, lack of exercise, noisy pollution, stressful life events such as accidents and death of relatives and friends.

\section{Coping Strategies of Stress}

The majority of the students reported that counseling was the best way to deal with stress.

"When I have a problem and feel stressed, I try to talk to an expert to find solutions for my problems." Indian, 21, female, single

The majority of the students reported that the meditation such as yoga, taichi and prayers were the best way to deal with stress. These also reported that sharing problems with others was among the best ways to deal with stress.

\section{"You need to share your problems with trustful person." Malay, 20, female, single}

The majority of the students reported that enough sleep and going out with friends were among the best ways to cope with stress. Some students reported that the aromatherapy was one of the ways to manage stress. Students involved in this study identified other coping strategies such as shouting, singing, time management, dancing, crying, massage, vacation, shopping, drinking a lot of water, watch cartons or comedies, eat chocolates, psychological treatment, optimistic thinking, and breathing. Other coping strategies reported were: healthy lifestyles such as eating a balance diet, regular exercise, avoiding tobacco consumption and alcohol drinking, practicing meditation such as yoga and taichi and listening to soft music. The surprising answer from one student reported salt intake to prevent stress.

\section{DISCUSSION}

We have decided to use focus group discussion to better understand factors that might be contributing to stress and to explore the strategies of coping with stress from students' perceptions. The associated factors causes of stress among students were financial, lack of sleep and family problems. The financial status of the students was one of the most associated factors related to causes of stress, this might be due to the financial crisis that affected the entire world and the rise in cost living. Same finding was reported by Bojuwoye, Ross et al, Gushae et al, Seyedfatemi et al, which indicated that the lack of financial support was one of the factors that contributed to stress among university students. ${ }^{19-22}$ Family problems were also one of the most associated factors related to causes of stress among students in this study. Same finding reported by other researchers that students also faced family problems which might affect their learning ability and academic performance. ${ }^{10,11}$ Similar finding was reported by Shaikh and others in which the most common associated factors related to causes of stress were relationship problems in college or family. ${ }^{23}$ Similar findings reported by Seyedfatemi et al, that divorced between students' parents were among the stressors. ${ }^{22}$

Coping strategies refer to the specific efforts, both behavioral and psychological, that people employ to master, reduce tolerate or minimize stressful events. ${ }^{24}$ The guidelines have stated that there are no standards for coping strategies, that might be vary depending on socio-cultural factors. On other hand, coping strategies have been shown to vary by region, community, social group, household, gender, age, season and time in history and are greatly influenced by individuals' previous experiences. ${ }^{25}$

Students in this study were able to describe a variety of strategies to cope with the stressful situations which include counseling, talking with friends, meditation, sharing problems, sleeping well and exercise. Regarding counseling, this study found that counseling is one of the coping strategies used by the students. A similar finding was reported by Seyedfatemi et al, that getting professional counseling and talking to a counselor were the common coping strategies used by nursing students in Iran. ${ }^{22}$ Similar finding reported among Black and Latino students. ${ }^{26}$ In terms of talking to the friends, it was the most common stress relieving factor in students. Friends as the most perceived social support for students. Among Black and Latino students, the most frequently reported coping strategies were talking with friends or parents, and participating in social activities. ${ }^{26}$ Among nurse students in Ireland, talking to relatives, friends and peers was the most common method of coping with stress. ${ }^{27}$ This might be because students spend more time in their university 
than at home. Students involved in this study identified meditation such as yoga to manage their stress; this might be due to the fact that the majority of the participants were Indians for whom yoga is commonly practiced among Indians, taichi reported among Chinese and prayers among Malays. Similar finding was reported among student nurse in Iran. ${ }^{22}$ Similar finding was reported by Chiang et al, that participating in religious activities was one of the coping strategies reported by students. ${ }^{26}$ Kang and others reported that a stress coping program based on mindfulness meditation was an effective intervention for nursing students to decrease their stress and anxiety and could be used to manage stress with students. ${ }^{27}$ Evans and Kelly and Dewe found a range of coping strategies similar to our findings which were described by the participants such as: talking to significant people or practicing some activities such as resting, sleeping, reading, walking or praying. ${ }^{28,29}$ Zeidner and Saklofske mentioned the following criteria for determining the effectiveness of stress coping strategies: resolution of the conflict or stressful situation, reduction of psychological distress, normative social functioning, returning to pre-stress activities, well-being of self and others affected by the situations, maintaining positive self-esteem, and perceived effectiveness. ${ }^{30}$ Regarding sleep, university students suffer from more sleep disturbances than general population due to the academic demand. Sleep difficulties among university students can lead to lower levels of performance and decrease of levels of well-being. Sleep appears to influence individuals' of coping strategies. Similar study found significant relations between sleep quality and coping.31 Regular exercise was reported by some students as a coping strategy, it might increase self-confidence and lower the symptoms related to mild depression and anxiety. 3 One important limitation of this study was that the participation in this drawn from the Faculty of Health and Life Sciences, MSU, Malaysia. Our findings cannot be generalized for students in other faculties.

\section{CONCLUSION}

Most of the students defined stress as "a mental condition". Lack of sleep, financial, and family problems were the most causes of stress. Students were able to identify some strategies to cope with stress such as meditation, enough sleeping, going out with the friends and counseling. Students require attending sessions to assist in improving their life and coping with stress such as time management and other stress related issues. Providing students with meaningful programs that assist in recognizing stress and identifying effective stress management strategies and also building programs about how to manage time will be important. Providing students with a first year course that addresses some of the issues pertaining to the experience of first year student will assist students to manage their stress.

\section{Acknowledgements}

The authors wish to thank all participants in this study. Gratitudes also extended to Mr. Mutee al-Sarory for checking the manuscript linguistically.

\section{REFERENCES}

1. Lazarus RS. Psychological stress and the coping process. New York: Springer, 1966.

2. Selye H. The Stress of Life. New York: McGrawHill, 1976.

3. Shah C, Trivedi RS, Diwan J, Dixit R, Anand AK. Common stressors and coping of stress by medical students. J Clin Diagn Res 2009; 3:1621-6

4. Hirsch JK, Ellis JB. Differences in life stress and reasons for living among college suicide ideates and non ideates. Coll Stud J 1996; 30:377-84

5. Kohn JP, Frozer GH. An academic stress scale: identification and rated importance of academic stressors. Psychol Rep 1986; 59:415-26

6. Sgan-Cohen HD, Lowental U. Sources of stress among Israeli dental students. J Am Coll Health Assoc 1988; 36:317-21

7. Wright JJ. Reported personal stress sources and adjustment of entering freshmen. J Couns Psychol 1967; 14:371-3

8. Supe AN. A study of stress in Medical students at Sheth GS Medical College. J Postgrad Med 1998; 44:1-6

9. Stewart SM, Beton C, Lan TH, Marshallk IB, Lee PW, Wong CM. Predicting stress in first year Medical students: a longitudinal study. Med Educ 1997; 31:163-8

10. Fish C, Nies MA. Health promotion needs of students in a college environment. Public Health Nurs 1996; 13:104-11

11. Chew-Graham CA, Rogers A, Yassin N. I would not want it on my CV or their records: Medical students' experiences of help-seeking for mental health problems. Med Educ 2003; 37:873-80

12. Lazarus RS, Folkman S. Stress, appraisal, and coping. New York: Springer, 1984.

13. Emilia1 ZA, Noor Hassim I. Work-related stress and coping: A Survey on Medical and surgical Nurses in a Malaysian teaching hospital. Jabatan Kesihatan Masyarakat 2007; 13:55-66

14. Uguak UA, Elias H, Uli J, Suandi T. Academic adjustment and psychological well-being among students in an international school in Kuala Lumpur, Malaysia. Jurnal Pendidikan. 2006; 127-39

15. Jani J. Coping stress and sports performance among school athletes in Kuala Langat District, Selangor. Jurnal Penyelidikan Pendidikan 2005; 7:113-25

16. Tharbe IH. Coping with stress: are our students proactive? Masalah Pendidikan 2006; 57-66

17. Sherina MS, Rampal L, Kaneson N. Psychological stress among undergraduate medical students. Med J Malaysia 2004; 59:207-11

18. Kamarudin R, Aris A, Ibrahim NA. Stress and 
academic performance: a study among prescience students in UiTM Negeri Sembilan. Conference on Scientific and Social Research 2009; 14-5

19. Bojuwoye O. Stressful experiences of first year students of selected universities in South Africa. Couns Psychol Q 2002; 15:227-90

20. Ross S, Cleland J, Macleod MJ. Stress, debt and undergraduate medical performance. Med Educ 2006; 40:584-9

21. Gushae J. Financial worries part of education for Memorial's medical students. Can Med Assoc J 1997; 157:559-62

22. Seyedfatemi N, Tafreshi M, Hagani H. Experienced stressors and coping strategies among Iranian nursing students. BMC Nursing 2007; 6:11

23. Shaikh BT, Kahloon A, Kazmi M, et al. Students, Stress and Coping Strategies: A Case of Pakistani Medical School. Educ Health 2004; 17:346-53

24. Sreeramareddy CT, Shankar PR, Binu VS, Mukhopadhyay C, Ray B, Menezes RG. Psychological morbidity, sources of stress and coping strategies among undergraduate medical students of Nepal. BMC Med Educ 2007; 7:26

25. WHO/EHA. Overview coping mechanisms in emergency health. Training programme for Africa. Panafrican Emergency Training Centre: Addis Ababa, 1999:3-13

26. Chiang L, Hunter CD, Yeh CJ. Coping attitudes, sources, and Practices among Black and Latino college students. Adolescence 2004; 39:793-815

27. Kang YS, Choi SY, Ryu E. The effectiveness of a stress coping program based on mindfulness meditation on the stress, anxiety, and depression experienced by nursing students in Korea. Nurse Educ Today 2009; 29:538-43

28. Evans W, Kelly B. Pre-registration diploma student nurse stress and coping measures. Nurse Educ Today 2004; 24:473-82

29. Dewe PJ. Identifying strategies nurses use to cope with work stress. J Adv Nurs 1987; 12: 489-97

30. Zeidner M, Saklofske D. Adaptive and Maladaptive Coping. In: Zeidner M and Endler N, eds. Handbook of Coping; Theory, Research, Applications. New York: John Wiley \& Sons, 1996

31. Word CA. Sleep quality of college students and its relationship to coping styles and well-being. $\mathrm{PhD}$ thesis. College of Education. Louisiana Tech University 2006. 
